\title{
Universal health coverage
}

\section{Preparation for the high-level meeting of the United Nations General Assembly on universal health coverage}

\author{
Report by the Director-General
}

1. The present report is submitted for the consideration of the Executive Board in keeping with the request made in paragraph 24 of resolution $72 / 139$, adopted in $2017,{ }^{1}$ in which the United Nations General Assembly decided to hold a high-level meeting on universal health coverage. ${ }^{2}$

\section{UNIVERSAL HEALTH COVERAGE: CRITICAL HEALTH AGENDA AROUND THE WORLD}

2. More than a decade into the 21 st century, the health community is grappling with epidemiological transition, game-changing statistics and technological trends. Recent statistics ${ }^{3}$ reveal that:

(a) at least half the world's population still lacks access to essential health services;

(b) some 800 million people spend more than $10 \%$ of their household budget on health care;

(c) almost 100 million people are pushed into extreme poverty each year because of out-of-pocket health expenses;

(d) on average, out-of-pocket payments represent about $32 \%$ of every country's health expenditure.

3. These facts have provoked a shift in traditional development thinking, which has long focused on the challenge of fighting disease. WHO continues to support this disease-oriented focus but notes the need to make space for additional challenges, in particular achieving universal health coverage and health system strengthening.

${ }^{1}$ See https://undocs.org/A/RES/72/139 (accessed 15 November 2018).

${ }^{2}$ Universal health coverage means that all people receive the health services they need, including public health services that are designed to promote better health, prevent illness and to provide treatment, rehabilitation and palliative care of sufficient quality to be effective, but that at the same time ensure that their use does not expose the user to financial hardship.

${ }^{3}$ Health statistics provided in the present report are taken from: World Bank Group/WHO. Tracking universal health coverage: 2017 global monitoring report. Washington, DC and Geneva; 2017. 


\section{UNIVERSAL HEALTH COVERAGE IN THE CONTEXT OF THE SUSTAINABLE DEVELOPMENT GOALS}

4. In the 2030 Agenda for Sustainable Development adopted by the United Nations General Assembly in September 2015, Member States renewed their commitment to promote the health and well-being of their populations. A number of the 17 Sustainable Development Goals of the 2030 Agenda have health-related targets, such as Goal 3 (Ensure healthy lives and promote well-being for all at all ages). Target 3.8 (Achieve universal health coverage, including financial risk protection, access to quality essential health care services and access to safe, effective, quality and affordable essential medicines and vaccines for all) is the key to attaining Goal 3 in its entirety, as well as the health-related targets of other Sustainable Development Goals.

5. Universal health coverage is both a goal in itself and a means for implementing other goals. It is crucial for tackling public health problems, in particular to ensure health system responses. The achievement of universal health coverage also holds potential for disease prevention and health promotion. Scaling up the implementation of public health interventions is therefore clearly the key to achieving universal health coverage.

6. Progress towards universal health coverage is a continuous process. Target 3.8 has two indicators: 3.8.1 on coverage of essential health services and 3.8.2 on the proportion of population with large household expenditures on health. These indicators represent the latest efforts to monitor the world's path towards universal health coverage.

\section{SERVICE COVERAGE}

7. The level of service coverage varies widely between countries. As measured by the UHC service coverage index, it is highest in East Asia (77) and North America and Europe (77), while sub-Saharan Africa has the lowest index value (42), followed by Southern Asia (53). The index is correlated with under-five mortality rates, life expectancy and the human development index.

8. Coverage of essential services has increased since 2000. Time trends for the UHC service coverage index are not yet available, but average coverage for a subset of nine tracer indicators used in the index for available time series increased by $1.3 \%$ per annum, roughly a $20 \%$ increase from 2000 to 2015 , of which the most rapid rates of increase were in coverage of antiretroviral treatment for HIV ( $2 \%$ in 2000 to $53 \%$ in 2016) and use of insecticide-treated nets for malaria prevention (1\% in 2000 to $54 \%$ in 2016). Although data limitations preclude precise measurement of the number of people with adequate service coverage, it is clear that at least half of the world's population do not have full coverage of essential services.

9. Regarding selected health services, more than 1 billion people have uncontrolled hypertension; more than 200 million women have inadequate coverage for family planning; and nearly 20 million infants fail to start or complete the primary series of diphtheria, tetanus, pertussis (DTP)-containing vaccine, and are therefore more likely to fail to receive other recommended vaccines.

\section{CATASTROPHIC SPENDING ON HEALTH}

10. Universal health coverage efforts in this area focus on two issues: "catastrophic spending on health", which is out-of-pocket spending (without reimbursement by a third party) that exceeds a household's ability to pay; and "impoverishing spending on health", which occurs when a household is 
forced by an adverse health event to divert spending away from non-medical budget items, such as food, shelter and clothing, to such an extent that it is considered to be living below the poverty line.

11. The incidence of catastrophic spending on health is reported in terms of two thresholds: out-of-pocket expenditures that exceed $10 \%$ of household total income or consumption and those that exceed 25\%. This is the approach adopted for the Sustainable Development Goals monitoring framework. At the global level, it is estimated that in 2010, 808 million people (some $11.7 \%$ of the world's population) incurred out-of-pocket health payments exceeding the $10 \%$ threshold, while 179 million (2.6\% of the world's population) incurred such payments exceeding the $25 \%$ threshold.

12. In 2010, the Western Pacific Region had the highest rate exceeding the 10\% threshold (14.8\%), while the South-East Asia Region had the second-highest rate exceeding the 10\% threshold (12.8\%) and the highest rate exceeding both the $10 \%$ and the $25 \%$ thresholds. The percentage and size of the global population facing catastrophic spending on health have increased at both thresholds since 2000: at the $10 \%$ threshold, the regions with the fastest increase in rates are the African and Eastern Mediterranean regions (+4.9\% per annum on average), followed by the Western Pacific Region (+3.6\% per year). The Region of the Americas is the only region where both the percentage and size of the population exposed to catastrophic spending on health decreased between 2005 and 2010 (-2.05\% per year on average).

\section{IMPOVERISHING SPENDING ON HEALTH}

13. Indicators of impoverishing spending on health are not part of the official Sustainable Development Goals indicator of universal coverage per se, but they link universal health coverage directly to Sustainable Development Goal 1 (End poverty in all its forms everywhere). These indicators, which are measured in international dollars (\$), are based on international poverty lines, specifically $\$ 1.90$ a day measured in 2011 purchasing power parity for extreme poverty and $\$ 3.10$ a day in 2011 purchasing power parity for moderate poverty. These two poverty lines are too low to capture impoverishment in upper middle- and high-income countries. The incidence of impoverishment has therefore been measured as the difference between the number of people in poverty with out-of-pocket spending included in household total consumption or income and the number of people in poverty without out-of-pocket spending included in household total consumption or income.

14. An estimated 97 million people were impoverished on health care at the $\$ 1.90$ a day poverty line in 2010 ( $1.4 \%$ of the world's population); at the $\$ 3.10$ a day poverty line, the figure was 122 million (1.8\%). At these two international poverty lines, impoverishment rates in upper-middle-income countries and high-income countries are close to or equal to zero. At the $\$ 1.90$ a day poverty line in 2010, the number and percentage of people impoverished worldwide fell between 2000 and 2010 from 130 million (2.1\%) to 97 million (1.4\%); by contrast, at the $\$ 3.1$ a day poverty line, both the percentage and number of people impoverished worldwide increased from 106 million (1.7\%) to 122 million $(1.8 \%)$.

15. In 2010, the South-East Asia and African regions had the highest rates of impoverishment at the $\$ 1.90$ a day poverty line (3.12\% and $1.65 \%$, respectively); at the $\$ 3.1$ a day poverty line, the South-East Asia and the Western Pacific regions had the highest rates of impoverishment. Between 2000 and 2010, the African and the Western Pacific regions saw reductions in the incidence of impoverishing spending on health at both the $\$ 1.90$ and $\$ 3.10$ a day poverty lines, while the South-East Asia Region saw a reduction at the $\$ 1.90$ a day poverty line $(-2.5 \%)$ and an increase at the $\$ 3.10$ poverty line $(+2.8 \%)$.

16. There is a need for strong, continuous political commitment and support, more government fiscal space specifically dedicated to health, more investment in health delivery systems, primary health care 
and a committed health workforce, and strengthened implementation capacities. All these elements are equally important to achieving universal health coverage.

17. As part of WHO's contribution both to the achievement of the 2030 Agenda for Sustainable Development, and to the promotion of a coordinated multisectoral approach to implement the Sustainable Development Goals, the Secretariat has been working with Member States and partners to implement WHO's Thirteenth General Programme of Work, 2019-2023. The Organization is also working with other international organizations to develop a "global action plan for healthy lives and well-being for all" with the aim of providing better support to Member States in their efforts to achieve the health- related Sustainable Development Goals, including target 3.8 on universal health coverage.

\section{SCOPE, MODALITIES, FORMAT AND ORGANIZATION OF THE HIGH-LEVEL MEETING}

18. In resolution 72/139, co-sponsored by 71 like-minded Member States, the General Assembly decided by consensus to hold a high-level meeting on universal health coverage in 2019 and requested the President of the General Assembly and the Director-General of WHO to work in close collaboration, in consultation with Member States, to prepare for the meeting with a view to ensuring the most effective and efficient outcomes, including potential deliverables.

19. At its seventy-third session, the General Assembly adopted resolution 73/131 on scope, modalities, format and organization of the high-level meeting on universal health coverage, which contains the following key provisions:

(a) the overall theme of the high-level meeting will be "Universal health coverage: Moving together to build a healthier world";

(b) the one-day high-level meeting will be held in New York on the day before the opening of the general debate of the General Assembly at its seventy-fourth session, from 9 a.m. to 1 p.m. and from 3 p.m. to 6 p.m, consisting of an opening segment, a plenary segment for general discussion, two multistakeholder panels and a brief closing segment;

(c) the themes of the multistakeholder panels will take into consideration the direction and outcomes of other proceeding health processes and initiatives as well as the interactive multistakeholder hearing, with a view to ensuring the most effective and efficient outcomes and potential deliverables and sharing experiences and lessons learned to address remaining implementation gaps;

(d) the high-level meeting will approve a concise and action-oriented political declaration, agreed in advance by consensus through intergovernmental negotiations;

(e) the President of the General Assembly, with the support of WHO and other relevant partners, is requested to organize and preside over an interactive multistakeholder hearing before end-July 2019, with the active participation of appropriate senior-level representatives of Member States, observers of the General Assembly, parliamentarians, representatives of local government, relevant United Nations entities, nongovernmental organizations in consultative status with the ECOSOC, invited civil society organizations, philanthropic foundations, academia, medical associations, the private sector and broader communities, ensuring the participation and voices of women, children, youth and indigenous leadership, as part of the preparatory process; 
(f) The General Assembly emphasized the need for the high-level meeting to complement and build on preceding and ongoing health processes and initiatives, including: the high-level meetings on HIV/AIDS, antimicrobial resistance, tuberculosis and noncommunicable diseases and welcomed the convening of the Global Conference on Primary Health Care (Astana, Kazakhstan, October 2018) which may contribute to the debates of the high-level meeting of the General Assembly on universal health coverage.

\section{PREPARATION OF OUTCOME DOCUMENTS OF THE HIGH-LEVEL MEETING}

20. In pursuance of the request in paragraph 24 of resolution $72 / 139$, the nature of WHO's support for the preparation of the outcomes of the high-level meeting will be guided by its governing bodies, high-level global/regional policy forums and partners in the preparation of a draft political declaration to achieve universal health coverage.

21. The main objectives of the preparatory process include:

(a) to allow Member States to engage in discussion and support the process to prepare a draft political declaration on achieving universal health coverage, for adoption at the high-level meeting;

(b) to translate political commitments already made into concrete commitments for action, including the improvement of implementation capacities for universal health coverage;

(c) to call upon all stakeholders to harmonize their support for Member States to realize universal health coverage progressively.

22. Issues covered by the draft political declaration may include concerns over stagnation in the implementation of universal health coverage and the need for its active implementation worldwide. Challenges may be identified and concrete actions proposed for the Secretariat, Member States and development partners. The draft declaration may also include an accountability framework that holds all actors, in particular governments, accountable to universal health coverage commitments. A monitoring and evaluation mechanism may be included to review progress towards universal health coverage at the country level in the three dimensions of population, service and cost coverage, to identify bottlenecks and to set benchmarks for follow-up until the Sustainable Development Goals' end-term, in 2030 .

23. As part of the preparatory process, WHO will support the President of the General Assembly in organizing and presiding over an interactive multistakeholder hearing before end-July 2019, as proposed in the resolution mentioned in paragraph 19 above, with the active participation of all partners. In addition, WHO will actively support and participate in relevant global and regional policy forums and compile inputs to the preparatory process from all partners, including the wider community, civil society organizations and the private sector.

24. In 2019, the January session of the Executive Board and the May meeting of the World Health Assembly will provide an essential contribution to informed discussion of the concrete actions required, paving the way for substantive decisions at the high-level meeting. 


\section{ACTION BY THE EXECUTIVE BOARD}

25. The Executive Board is invited to note the report. It is also invited to focus its discussions on providing strategic directions that will enable the global community to make a coordinated effort towards achieving universal health coverage.

$$
=\quad=
$$

